\title{
Study of Antioxidant Effectiveness of Kraft Lignin in HDPE
}

\author{
I. Piña, ${ }^{1}$ F. Ysambertt, ${ }^{2}$ D. Perez, ${ }^{2}$ and K. Lopez ${ }^{2}$ \\ ${ }^{1}$ Laboratory of Chemical Analysis and Electrochemistry, Department of Chemistry, Faculty of Engineering, \\ University of Zulia, Maracaibo 4001, Venezuela \\ ${ }^{2}$ Laboratory of Analytical Instruments, Department of Chemistry, Faculty of Sciences, University of Zulia, \\ Maracaibo 4001, Venezuela \\ Correspondence should be addressed to I. Piña; iramasaenz@gmail.com
}

Received 15 May 2015; Revised 4 July 2015; Accepted 5 July 2015

Academic Editor: Yves Grohens

Copyright (C) 2015 I. Piña et al. This is an open access article distributed under the Creative Commons Attribution License, which permits unrestricted use, distribution, and reproduction in any medium, provided the original work is properly cited.

Polymers are subject to oxidative degradation during all steps of their useful cycle. This degradative process is prevented using stabilizers like antioxidant of the type sterically hindered phenols or amines. Lignin, due to the presence of phenolic groups in their structure, can present characteristic as antioxidant agent, in a similar way to the additives used in polymers. Therefore, in this work, the antioxidant capacity of the lignin in a sample of polyethylene is studied. For this reason, in this paper, a method based on nonisothermal differential scanning calorimetry (DSC) to evaluate this property is used. The samples studied were subjected to heat treatment at different scan rates and in presence of oxygen to promote thermooxidation of the material. The antioxidant capacity of different formulations of lignin and additives in the polymer resin was determined from the temperature of onset of oxidation $\left(T_{i}\right)$ at different heating rates and adjusting Arrhenius model prediction. The results indicate that the procedure can predict the antioxidant capacity of antioxidant additives in HDPE with good reproducibility and accuracy, according to the Arrhenius model prediction.

\section{Introduction}

The high density polyethylene (HDPE) is exposed to oxidative degradation during all stages of its life cycle, from its synthesis, storage, and processing to end use. The antioxidant stabilizers include hindered phenols systems and radical scavengers are widely used in the plastics industry for the photostabilization of polyolefin (as discussed elsewhere [1$3]$ ). Due to the presence of phenolic groups in the lignin structure, we can assume that this macromolecule may present a behavior as an antioxidant. This natural biopolymer represents $16 \%$ to $33 \%$ of the weight of the wood, depending on this one (Figure 1). Industrially, in the manufacture of paper and other products, it is necessary to remove the lignin from the wood, hence the attractiveness of their evaluation for possible use as an antioxidant in formulations of HDPE. Of the different existing thermal analysis methods, the most commonly used method for determination of polymer stability is thermogravimetric analysis. However, several authors have determined the oxidative induction time using differential scanning calorimetry (DSC).

Various authors have demonstrated the effectiveness of the antioxidant in the polymer matrix through studying thermooxidative nonisothermal conditions by DSC. This study is related to the temperature dependence and the induction period (IP), which may depend on the Arrhenius equation (as discussed elsewhere [4-9]):

$$
t_{i}=A \exp \left[\frac{B}{T}\right]
$$

where $t_{i}$ is the induction period (IP), $A$ and $B$ are constant, and $T$ is the absolute temperature. In the linear case, to increase the temperature, parameters $A$ and $B$ are obtained by the following equation:

$$
\beta=\int_{0}^{T_{i}} \frac{d T}{A} \exp \left[\frac{B}{T}\right]
$$




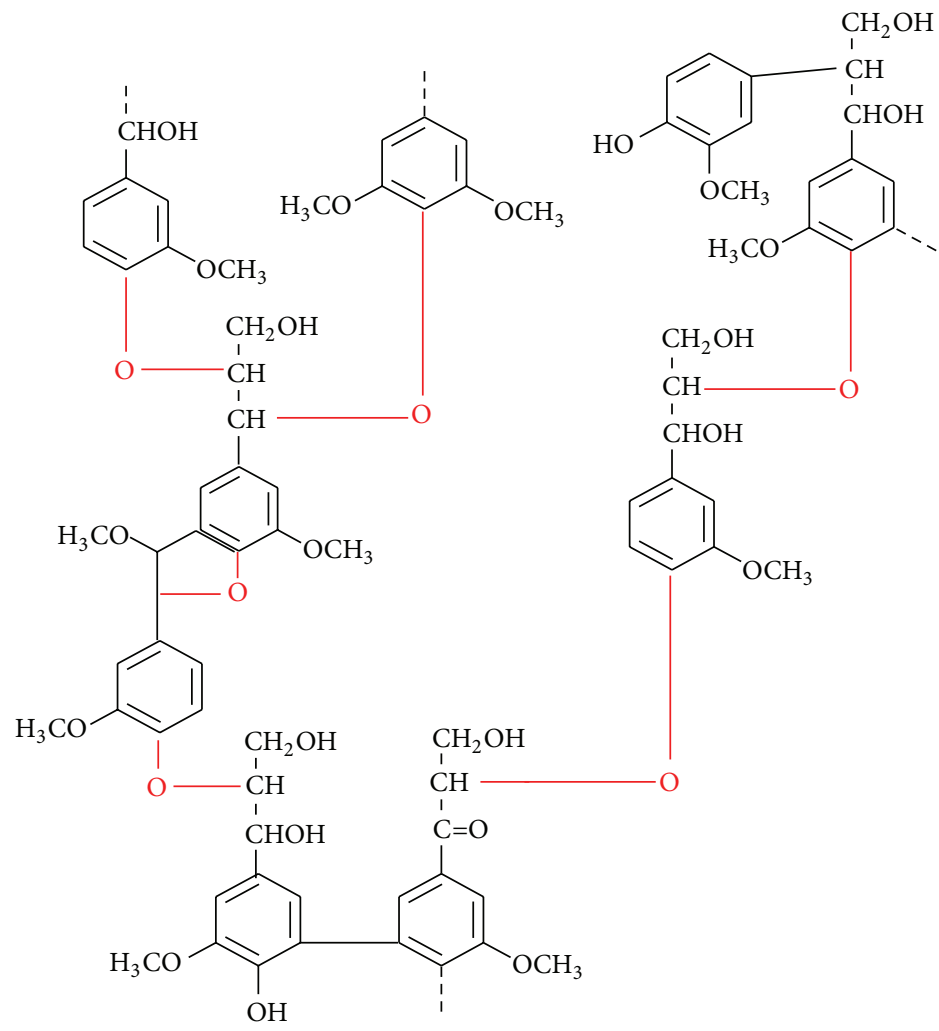

Figure 1: Model of soft wood lignin structure.

where $T_{i}$ is the temperature of onset of oxidation peak and $\beta$ is the heating rate. Calculating induction time, the protection factor $(\mathrm{PF})$ is determined by the following equation:

$$
\mathrm{PF}=\frac{t_{i}\left(P_{\text {stab. }}\right)}{t_{i}(P)},
$$

where $t_{i}\left(P_{\text {stab. }}\right)$ and $t_{i}(P)$ are the induction period of stabilized and nonstabilized polymer, respectively. Once these values are obtained, it is possible to calculate the effectiveness of the antioxidant (AEX) based on PF according to the expression:

$$
\mathrm{AEX}=\mathrm{PF}-\frac{1}{X}
$$

where $X$ is the molar concentration of the additive in the polymer matrix.

For all the above, this paper proposes a method based on nonisothermal DSC to evaluate the antioxidant capacity of lignin in samples of HDPE. The samples under study were subjected to heat treatment at different scan rates and in the presence of oxygen to promote thermooxidation of the material.

\section{Methodology}

2.1. Materials and Reagents. Solvents were used: dichloromethane, HPLC grade $\left(\mathrm{CH}_{2} \mathrm{Cl}_{2}\right.$, Fischer Sci., 99\%), hydrochloric acid (Riedel-de Haen, 37\%), phosphoric acid (Contact-Hazard, 85\%), acetic acid (Fischer Sci., 99\%),
Aldrich commercial lignin (98\%, Mn 28000 Daltons), and dimethylsulfoxide (DMSO, Fischer Sci., 99\%). The lignin used was obtained through the black liquor from the papermaking industry Smurfit, Mocarpel Cartón de Venezuela S. A., through an acid precipitation. HDPE (free additive) was used as polymeric matrix, produced by Polinter (Venezuela), a density of $0.9580 \mathrm{~g} / \mathrm{cm}^{3}$ and melt index of $0.40 \mathrm{~g} / 10 \mathrm{~min}$ $\left(190^{\circ} \mathrm{C} / 2.16 \mathrm{~kg}\right)$. A Brazil commercial antioxidant Ciba Irganox 1010 (I1010) was used as additive. For the evaluation of the antioxidant capacity, the following types of equipment were used: pilot extruder, Brabender model PLE-650, $L / D=26$ and $D=19 \mathrm{~mm}$, for melt mixing, differential scanning calorimeter, and TA Instruments model 2910.

2.2. Isolation and Characterization of Lignin Extracted from Black Liquor. $100 \mathrm{~mL}$ of black liquor $(\mathrm{pH}=11.48)$ was taken and diluted in distilled water $(1: 1)$ with constant stirring at room temperature; then, $\mathrm{pH}$ was adjusted to about 5 using concentrated acid $\left(\mathrm{HCl}, \mathrm{H}_{3} \mathrm{PO}_{4}\right.$, and $\left.\mathrm{CH}_{3} \mathrm{COOH}\right)$. The precipitated lignin was centrifuged at $5000 \mathrm{RPM}$ for $15 \mathrm{~min}$ to remove the resulting solid. It was washed several times with distilled water to obtain a clear supernatant; the solid obtained was dried overnight in the oven at $45^{\circ} \mathrm{C}$.

The samples obtained (LLN) were finely ground and stored in containers amber and then analyzed and compared with the commercial Aldrich lignin (LA). The characterizations of these lignins were realized through infrared (FTIR), differential scanning calorimetric (DSC), and Size Exclusion Chromatography (SEC). 
FTIR spectra were taken in the solid state using $\mathrm{KBr}$ pellets (Riedel-de Haen, 98\%), on a Shimadzu FTIR model 8400. The chromatographic studies were performed using THF (JT Baker, 99.9\%) as solvent, and as mobile phase, in a Waters liquid chromatograph formed by an injector Universal U6K, a quaternary pump Waters Model $600 \mathrm{E}$, a PDA (Photodiode Array detector) detector, and a personal computer with Millenium 32 software; in this study, a set of columns Zorbax PSM 60-S (selective permeation range 6010000 Daltons) and PSM 300-S (selective permeation range 1000-300000 Daltons) (Agilent) was used with a package of silica porous microsphere $5 \mu \mathrm{m}(6.2 \mathrm{~mm}$ id $\times 25 \mathrm{~cm})$. All thermal evaluations were performed on a Rheometric Scientific Differential Scanning Calorimeter.

2.3. Mixing Procedure. Physical mixing for the following samples was made:

(i) HDPE + lignin $2000 \mathrm{ppm}$ and $800 \mathrm{ppm}$.

(ii) HDPE + Irganox 1010 (I1010) 800 ppm.

(iii) HDPE + I1010/lignin 50:50 800 ppm.

The preparation of these mixtures was carried out as follows: lignin in $1 \mathrm{~mL}$ of dimethylsulfoxide (DMSO) was dissolved and then added in $100 \mathrm{~mL}$ of dichloromethane $\left(\mathrm{CH}_{2} \mathrm{Cl}_{2}\right)$; this solution was added to HDPE, leaving an automatic mixer for $30 \mathrm{~min}$ (medium speed) to evaporate solvent. Subsequently, the mixture is led to an extruder to proceed with melt blending, in order to obtain a better dispersion of lignin in the polymer matrix. The melt blending conditions were as follows: temperature profile of 170-180$190^{\circ} \mathrm{C}$ at $50 \mathrm{rpm}$ for $30 \mathrm{~min}$ in the extruder pilot.

2.4. Study of Antioxidant Capacity by DSC. All tested samples were analyzed using the following procedure: $4 \mathrm{mg}$ sample to be subjected to heat treatment at different heating rates $\left(\beta=3,5,10,15\right.$, and $\left.20^{\circ} \mathrm{C} / \mathrm{min}\right)$ in the presence of $10 \mathrm{~mL} / \mathrm{min}$ of oxygen to promote thermooxidation of the material using a temperature range between 50 and $350^{\circ} \mathrm{C}$. From initiation temperature oxidation $\left(T_{i}\right)$ at different heating rates and an adjustment of a prediction model Arrhenius type protection factor and antioxidant effectiveness of lignin in the polymer resin were determined, which may be conducted by using a computer program written in FORTRAN-77 (called KINPAR) which was generously provided by Dr. Šimon, Department of Physical Chemistry, Faculty of Chemical and Food Technology, Slovak University of Technology in Bratislava (as discussed elsewhere [4]).

\section{Results and Discussion}

The FTIR spectra of the isolated lignin from black liquor had the same signals as the LA sample. These signals correspond to stretching vibration of $\mathrm{OH}$ (hydrogen bonding) to 3440 $3430 \mathrm{~cm}^{-1}$, aliphatic $\mathrm{CH}\left(\mathrm{CH}\right.$ and $\mathrm{CH}_{2}$ groups) at 2940 $2930 \mathrm{~cm}^{-1}, \mathrm{C}=\mathrm{C}$ aromatic bonds $\left(1610-1690 \mathrm{~cm}^{-1}\right)$, aliphatic $\mathrm{CH}$ bonds $\left(\mathrm{CH}\right.$ or $\mathrm{CH}_{2}$ groups) at $1458 \mathrm{~cm}^{-1}$, carbonyl signal at $1710 \mathrm{~cm}^{-1}(\mathrm{C}=\mathrm{O}), \mathrm{CO}$ links (guaiacyl ring) to $1210 \mathrm{~cm}^{-1}$

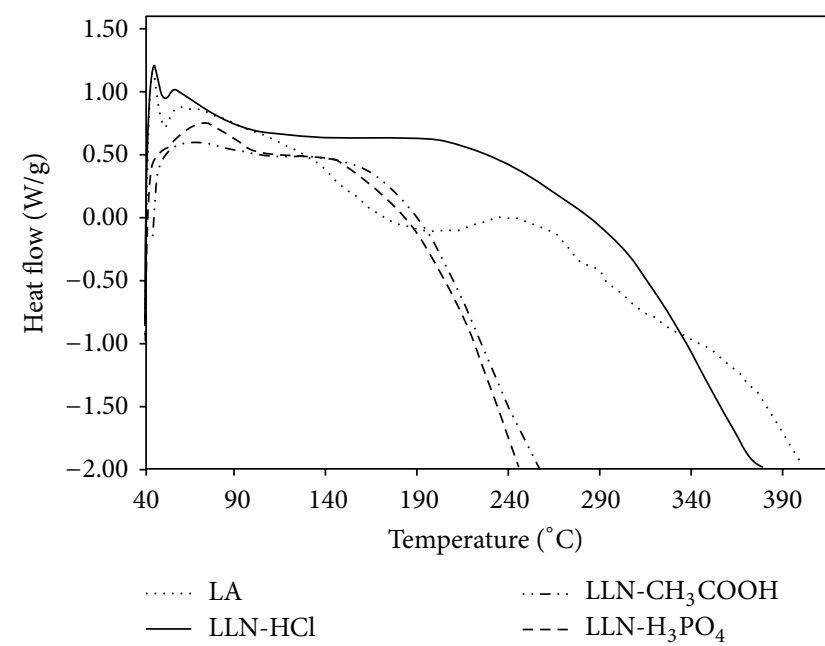

FIGURE 2: Thermal behavior of the obtained lignin fractions with different acids. Conditions: $\mathrm{N}_{2}$ gas to $10 \mathrm{~mL} / \mathrm{min}$, heating rate $10^{\circ} \mathrm{C} / \mathrm{min}$, and range from 40 to $400^{\circ} \mathrm{C}$.

links of secondary alcohols to $1170 \mathrm{~cm}^{-1}$ (CO), and a signal at $615 \mathrm{~cm}^{-1}$ for the $\mathrm{C}-\mathrm{Cl}$ bond. These signals are consistent with studies reported in the literature (as discussed elsewhere $[11,12])$.

An unpublished study (as discussed elsewhere [13]) demonstrated that precipitation with hydrochloric acid is the most appropriate, because it is an acid which does not tend to hydrolyze lignin at room temperature and can help hydrolyze cellulose and hemicelluloses into smaller chains. Comparing the spectrum LLN-HCl with commercial lignin LA showed that LLN-HCl is slightly degraded; this may be due to severe Kraft delignification process, which causes degradation of some functions to carboxylic acids (aliphatic and aromatic), thereby affecting molecular mass distribution of the biomolecule. Table 1 shows the signal characteristics of the LA and LLN precipitated with acid, in the infrared region, which are consistent with studies reported in the literature (as discussed elsewhere $[10,14,15])$.

The thermal behavior of extracted lignins compared to commercial lignin (Figure 2) shows that the lignin- $\mathrm{HCl}$ LLN presents thermal resistance similar to the product LA, because the curves do not decay as rapidly as with other lignin products. This behavior can be attributed probably to the lignins extracted with acetic acid and phosphoric acid may have suffered bond breaking, causing a decreasing molecular weight compared with lignin LA.

It is worth noting that this behavior is easy to infer when we observe molecular size distribution curves shown in Figure 3. For the evaluation by SEC, it was necessary to perform acetylation samples prior to analysis, to make them more soluble in organic media and using THF as the mobile phase in the chromatographic system. This together with the use in series of stationary phases Zorbax PSM 60 and 300 allowed for minimizing permeation of large molecules (molecular associations minimization), which would cause the onset of bimodals molecular distribution curves (as discussed elsewhere [16-19]). 
TABLE 1: Signal in the infrared region for precipitated lignins.

\begin{tabular}{|c|c|c|c|c|c|}
\hline \multirow{2}{*}{${ }^{*}$ Signal $\left(\mathrm{cm}^{-1}\right)$} & \multirow[b]{2}{*}{ Functional group } & \multicolumn{4}{|c|}{ Maximum of the signal $\left(\mathrm{cm}^{-1}\right)$} \\
\hline & & LA $^{*}$ & LLN-HCl & $\mathrm{LLN}-\mathrm{CH}_{3} \mathrm{COOH}$ & LLN- $\mathrm{H}_{3} \mathrm{PO}_{4}$ \\
\hline $3440-3430$ & $\nu \mathrm{O}-\mathrm{H}$ (hydrogen bonding) & 3408,0 & 3440,0 & 3439,6 & 3438,1 \\
\hline $\begin{array}{l}2940-2930 \\
2689-2880\end{array}$ & $\begin{array}{l}v \mathrm{C}-\mathrm{H} \text { aliphatic }\left(\text { groups } \mathrm{CH} \text { and } \mathrm{CH}_{2} \text { ) }\right. \\
v \mathrm{C}-\mathrm{H} \text { (groups } \mathrm{CH}_{3} \text { from } \mathrm{OCH}_{3} \text { ) }\end{array}$ & $\begin{array}{l}2937,4 \\
\text { (Overlapped) }\end{array}$ & $\begin{array}{l}2940,3 \\
2846,7\end{array}$ & $\begin{array}{l}2939,0 \\
2847,0\end{array}$ & $\begin{array}{l}2938,0 \\
2846,0\end{array}$ \\
\hline \multirow{2}{*}{$1727-1690$} & \multirow{2}{*}{$\nu \mathrm{C}=\mathrm{O}$} & \multirow{2}{*}{ (Very weak) } & 1710,7 & 1710,8 & 1710,9 \\
\hline & & & 1647,1 & 1648,1 & 1649,1 \\
\hline $1610-1690$ & $\nu \mathrm{C}=\mathrm{C}$ aromatic & 1598,9 & 1610,7 & 1608,0 & 1609,8 \\
\hline 1505 & $\gamma \mathrm{C}-\mathrm{H}$ aromatic on the plane & 1512,1 & 1512,1 & 1510,1 & 1510,0 \\
\hline 1458 & $\gamma \mathrm{C}-\mathrm{H}$ aliphatic (groups $\mathrm{CH}$ or $\mathrm{CH}_{2}$ ) & 1458,1 & 1460,0 & 1459,0 & 1459,8 \\
\hline $1425-1420$ & $\gamma \mathrm{C}-\mathrm{H}$ aliphatic (groups $\mathrm{CH}_{3}$ ) & 1429,2 & 1425,3 & 1422,3 & 14245,8 \\
\hline \multirow{2}{*}{$1370-1250$} & $\gamma \mathrm{O}-\mathrm{H}$ & 1369,4 & 1367,4 & 1367,1 & 1367,5 \\
\hline & $v \mathrm{C}-\mathrm{O}$ (syringyl ring) & 1220,9 & 1218,9 & 1219,0 & 1218,1 \\
\hline 1260 & $v \mathrm{C}-\mathrm{O}$ (guaiacyl ring) & 1271,0 & 1269,1 & 1269,9 & 1269,9 \\
\hline $1160-1140$ & $v \mathrm{C}-\mathrm{O}$ (secondary alcohol) & 1126,4 & 1120,6 & 1125,6 & 1125,0 \\
\hline 1044 & $\nu \mathrm{C}-\mathrm{O}$ (primary alcohol) & 1033,8 & 1033,8 & 1033.8 & 1033.8 \\
\hline 844 & $\gamma \mathrm{C}-\mathrm{H}$ aromatic outside the plane (wide) & 858,6 & 860,2 & 860,2 & 860,2 \\
\hline 620 & $\nu \mathrm{C}-\mathrm{Cl}$ (hydrochloric acid) & - & 615 & - & - \\
\hline
\end{tabular}

${ }^{*}$ Reference signals (Aldrich lignin) in lignin (as discussed elsewhere [10]).

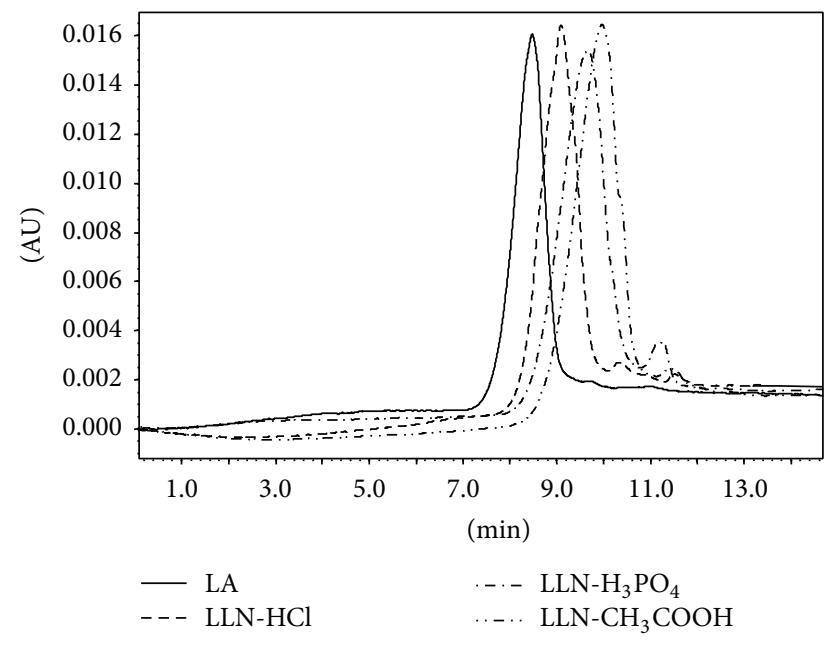

FIGURE 3: SEC chromatograms for lignin fractions obtained with different acids. Conditions: mobile phase: THF $1 \mathrm{~mL} / \mathrm{min}$, detector: PDA $280 \mathrm{~nm}$, injection volume: $50 \mu \mathrm{L}$, and columns Zorbax PSM $60-\mathrm{S}$ and $300-\mathrm{S}$.

In Figure 3, we can observe a single mode behavior for commercial lignin and bimodal for extracted lignins. Lignins $\mathrm{B}$ and $\mathrm{C}$ have lower molecular size compared with lignin $\mathrm{A}$ and are in turn smaller than LA. These results indicate that the lignins extracted with acetic and phosphoric acids showed a break in the macromolecule chains by acid catalysis and subsequent nucleophilic attack on the links alkyl aryl ether, confirming what was observed in the thermal analysis and spectroscopic results.

The results presented show that the lignin obtained by acid precipitation with $\mathrm{HCl}$ showed similar characteristics
TABLE 2: Statistical results of repeatability in the onset temperature for the oxidation of HDPE without additive.

\begin{tabular}{lrrrrrr}
\hline \multirow{2}{*}{$\beta\left({ }^{\circ} \mathrm{C} / \mathrm{min}\right)$} & \multicolumn{6}{c}{ Onset temperature oxidation $\left(T_{i},{ }^{\circ} \mathrm{C}\right)$} \\
& Run 1 & Run 2 & Run 3 & $X$ & SD & RSD (\%) \\
\hline 3 & 210,18 & 210,09 & 210,15 & 210,1 & 0,046 & 0,0002 \\
5 & 215,35 & 215,40 & 215,39 & 215,4 & 0,026 & 0,0001 \\
10 & 223,80 & 223,75 & 223,78 & 223,8 & 0,025 & 0,0001 \\
15 & 226,35 & 226,30 & 226,31 & 226,3 & 0,026 & 0,0001 \\
20 & 230,10 & 230,15 & 230,11 & 230,1 & 0,026 & 0,0001 \\
\hline
\end{tabular}

$X=$ average, $\mathrm{SD}=$ standard deviation, and $\mathrm{RSD}=$ relative standard deviation (\%).

to the commercial lignin. For this reason, this lignin was selected for evaluation of the studies of antioxidant effectiveness in blends with HDPE.

To evaluate the repeatability of $T_{i}$ determined by DSC thermograms, several replicas were made without additive in HDPE to different heating rates. In Table 2, the statistical analysis and repeatability in the determination of $T_{i}$ results are shown.

Statistical analysis showed that the analysis is repeated, with excellent accuracy in the determination of $T_{i}$, because it has a low standard deviation (0.025 to 0.046$)$ and a very low percentage of DER (0.0001 to 0.0002). In Figure 4, the change of $T_{i}$ as a function of heating rate for HDPE with different concentrations of lignin and commercial antioxidant is shown. It can be seen that with respect to HDPE without additive there is an increase of $T_{i}$ in polymer blends with lignin, which indicates the behavior as an antioxidant having the same.

A further increase of $T_{i}$ in the mixture of HDPE made with I1010 is also observed in Figure 4, which was attributed 


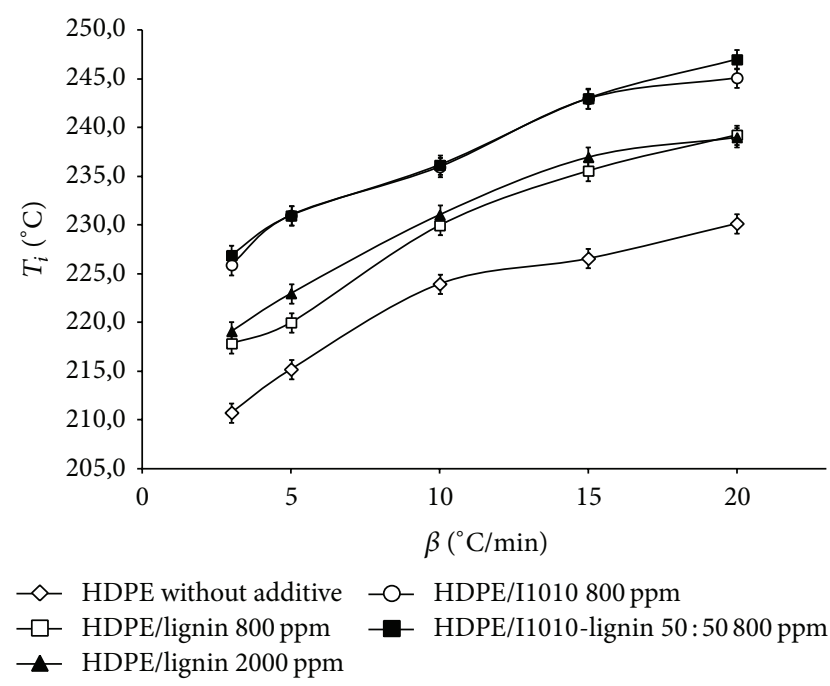

FIgURE 4: Variation of $T_{i}$ with the heating rate for the mixture of HDPE at different concentrations of lignin and commercial antioxidant.

to the antioxidant trade having a less complex structure as compared with the structure of lignin, a property that allows them to be inserted into only part of the polymer surface by having a smaller molecular weight, forming a protective monolayer (as discussed elsewhere $[1,7-9,20]$ ), which provides greater $T_{i}$ in a shorter time.

For the case of lignin, it is a complex three-dimensional molecule with large molecular weight and higher hydrophobicity than the I1010, which when mixed with the polymer may diffuse directly into the polymer matrix leaving less cover the surfaces of the polymer (as discussed elsewhere [21, 22]), but protects the inside of the long term. Thus, it can be seen that increasing almost tripled lignin concentration in the polymer matrix $(2000 \mathrm{ppm})$, no greater antioxidant effect is obtained.

Taking into account these assumptions and arguments, a mixture of HDPE was prepared with 50:50 lignin and I1010 at a total concentration of $800 \mathrm{ppm}$, because in many cases the antioxidants are not used alone but in combination with other antioxidants of the same or different types, in order to obtain greater efficiency of the antioxidant system (synergism). However, this is not always favorable since there are cases where the effect observed when employing two or more antioxidants is unfavorable (antagonism) (as discussed elsewhere $[23,24])$. In Figure 4, it is worth noting that the lignin 50:50 I1010 + antioxidant behavior developed greater than any of the tested mixtures; namely, a case of synergism was evident in the sample.

Moreover, it is necessary to bear in mind that the rate of degradation by a process of thermal oxidation in HDPE, in general, can be described by the kinetic expression (as discussed elsewhere [3-6, 22]):

$$
\frac{d_{\alpha}}{d_{t}}=k f(\alpha)
$$

with $\alpha$ being conversion, $f(\alpha)$ conversion function, and $k$ the rate constant of thermooxidative degradation. The dependence of the rate constant with temperature is generally assumed to be described by the Arrhenius equation, as expressed in the following:

$$
k=\left[-\frac{E_{a}}{R T}\right],
$$

where $k$ is the preexponential factor, $E_{a}$ is the activation energy, $T$ is the absolute temperature, and $R$ is the universal gas constant. Combining (5) and (6), after separation of variables and integration (assuming the isoconversion is independent of the temperature), resulted in

$$
1=\int_{0}^{t_{i}} \frac{d_{t}}{A \exp \lfloor B / T\rfloor}
$$

where $t_{i}$ is the induction period and the constants $A$ and $B$ are given by

$$
\begin{aligned}
& A=\frac{F\left(\alpha_{i}\right)-F(0)}{A k} \\
& B=\frac{E_{a}}{R} .
\end{aligned}
$$

In the description of the constant $A, F(\alpha)$ is the original function of $1 / f$ and $\alpha_{i}$ is the reaction conversion during the induction period IP. From (7), it follows that in the special case of an isothermal process the denominator is a constant value equivalent to the induction period at a given temperature. Therefore, the dependency of the induction period with the temperature can be described by (1).

In experiments carried out in this work, it was assumed that the oven temperature of the calorimeter is equal to the temperature of the sample under thermooxidative degradation. Thus, the linear increase of the calorimeter temperature corresponds to the linear increase in temperature in the sample being tested and is expressed by

$$
T_{f}=T_{0}+\beta_{t}
$$

where $T_{f}$ is the oven temperature, $T_{0}$ is the initial temperature measurement, and $\beta_{t}$ is the heating rate. Combining (7) and (9) results in (2), where $T_{i}$ is the temperature of onset ("onset temperature") of the oxidation peak in the thermogram. The KINPAR program was used for the determination of kinetic parameters $A$ and $B$ in (2). In the algorithm used, these parameters are obtained by minimizing the sum of squares between the theoretical values and the experimental values of the isoconversional temperatures determined at different heating rates by the simple method.

Working out substitutions respective $A$ and $B$ in (1) results in the induction period. The temperature range for HDPE thermooxidative stability as described above differs from the actual development predictable range HDPE thermooxidative stability because changes in temperature can lead to changes in the reaction mechanism and alter the function isoconversional. Consequently, an estimate of the 
TABLE 3: Kinetic parameters $A$ and $B$ for the different mixtures analyzed.

\begin{tabular}{lcc}
\hline Sample & $A(\min )$ & $B(\mathrm{~K})$ \\
\hline HDPE without additive & $3,66 E-15$ & $1,68 E+04$ \\
HDPE/lignin 800 ppm & $3,77 E-15$ & $1,70 E+04$ \\
HDPE/lignin 2000 ppm & $3,78 E-15$ & $1,70 E+04$ \\
HDPE/I1010 800 ppm & $3,88 E-15$ & $1,72 E+04$ \\
HDPE/I1010-lignin 50:50 800 ppm & $3,89 E-15$ & $1,72 E+04$ \\
\hline
\end{tabular}

absolute values of the induction period may lead to unreliable conclusions.

To overcome the problem arising in the above, and following proposed by Šimon et al. (as discussed elsewhere [4]), a comparison between the induction periods of HDPE stabilized and HDPE nonstabilized was established because the moiety responsible for the degradation of the material should be the same in both cases. This relationship is called the protection factor (PF), according to (3). As shown in (1), the induction periods are dependent on temperature and therefore also PF. According to (3), if the PF value is greater than unity, lignin alone or in combination with a commercial additive has stabilizing effect on the polymer, so this effect will be greater when the PF value increases.

Starting from initiation temperature oxidation $\left(T_{i}\right)$ and protection factor antioxidant effectiveness of lignin in the polymer resin was determined. This was done at different heating rates $\left(\beta=3,5,10,15\right.$, and $\left.20^{\circ} \mathrm{C} / \mathrm{min}\right)$ using the model described above to thermooxidative degradation kinetics isoconversional fitted to the Arrhenius equation. This study relates to the temperature dependence of the induction period $\left(t_{i}\right)$, according to (1). The kinetic parameters shown in Table 3 were determined through experimental $T_{i}$ at different $\beta$ with computer program called KINPAR.

With these kinetic data, the induction period was determined and then the protection factor $(\mathrm{PF})$ and the antioxidant effectiveness (AEX) of the lignin in the polymeric resin were estimated, as described according to (4). Figure 5 shows the behavior protection factor as a function of temperature for HDPE formulated with lignin and commercial antioxidant.

In this figure, it is important to emphasize several results:

(1) First of all, we observe that, with increasing temperature, the protection factor decreases.

(2) The protection factor of the mixture formulated with lignin HDPE 800 and 2000 ppm exhibits the same behavior, which allows for deducing that, with a high concentration of lignin in the polymer matrix, no significant increase in antioxidant capacity is observed.

(3) HDPE blend formulated with I1010 showed a higher protection factor compared to other formulations containing lignin only.

(4) The greatest protection factor of the analyzed mixtures was exercised by the $50: 50$ mixture of lignin and commercial antioxidant $800 \mathrm{ppm}$ in the HDPE.

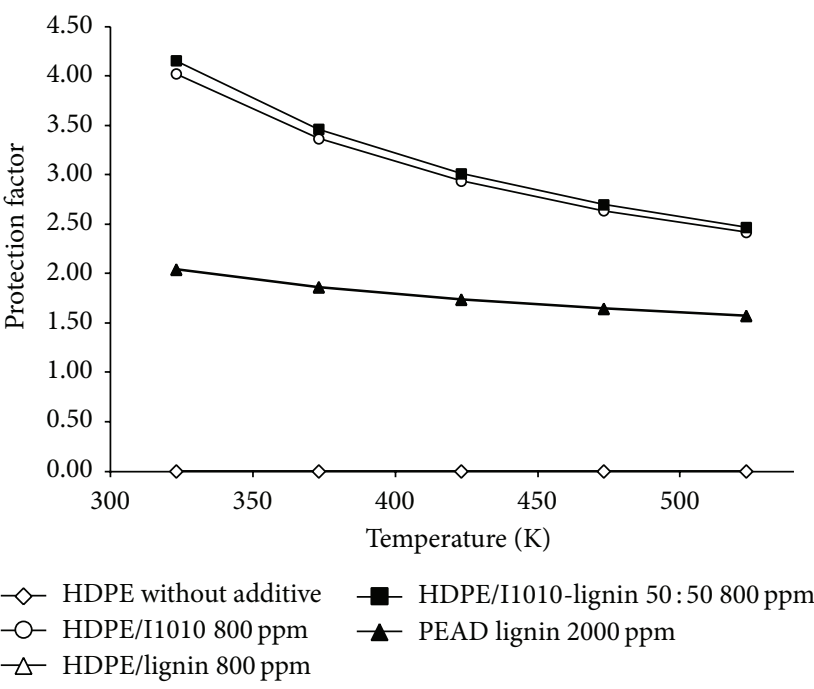

FIGURE 5: Variation of the protection factor as a function of temperature for the HDPE formulated with lignin and commercial antioxidant.

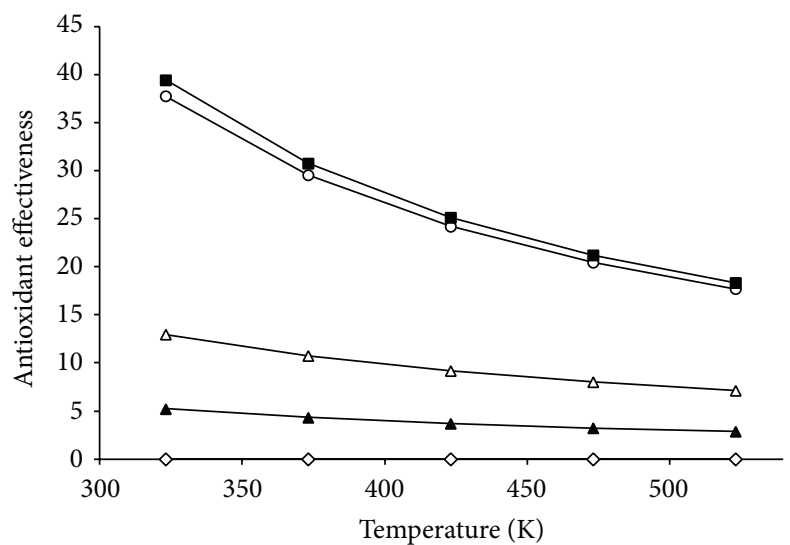

$$
\begin{array}{ll}
\checkmark \text { HDPE without additive } & \checkmark \text { HDPE/lignin } 800 \mathrm{ppm} \\
-0 \text { HDPE/I1010 800 ppm } & - \text { HDPE/lignin 2000 ppm } \\
\neg \text { HDPE/I1010-lignin 50:50 800 ppm } &
\end{array}
$$

FIGURE 6: Variation of the antioxidant effectiveness in function of the temperature for mixtures of lignin and HDPE formulated with a commercial antioxidant.

According to these results, it can be stated that the concentration of $800 \mathrm{ppm}$ is adequate to provide good protection factor in the polymer matrix of HDPE. Moreover, from the results obtained for protection factor of each of the samples tested, the antioxidant effectiveness of both lignin and commercial antioxidant and the 50:50 mixtures of both in the HDPE were calculated. The results for the tested antioxidant effectiveness are shown in Figure 6; in this figure, it can be seen that as for the protection factor values are decreasing as temperature increases.

According to the results observed in Figure 6, it can be stated that for the samples made with the mixture of HDPE and antioxidant effectiveness lignin exists. This effectiveness increases as it increases the amount of lignin in the polymer 
matrix reaching a peak at $800 \mathrm{ppm}$. Starting from this value, the effectiveness decreases. This is attributed to that, the greater the amount of lignin in the polymer matrix is less antioxidant capacity, for this reason, the proper amount of lignin in the HDPE is $800 \mathrm{ppm}$ for this study.

It also shows that for the corresponding mixture of HDPE with $800 \mathrm{ppm}$ of a commercial antioxidant there is greater effectiveness than that observed in the mixtures made with only lignin due to reasons relating to differences in molecular weights before explained.

Finally, it is worth noting that with a 50:50 mixture lignin/I1010 it was having the most effective antioxidant capacity at a concentration of $800 \mathrm{ppm}$ in HDPE. According to these results is thought that a synergistic effect between lignin and I1010 occurs, which causes an increase in the antioxidant capacity of this mixture with the HDPE.

\section{Conclusion}

The nonisothermal DSC thermooxidative study permitted knowing the antioxidant capacity of lignin in HDPE. Also, the protection factor and antioxidant effectiveness of lignin in HDPE and commercial antioxidant mixture and lignin 50:50/11010 were determined by Arrhenius type model prediction. These results demonstrate that lignin has a lower antioxidant capacity compared with the commercial additive because unlike them it has a higher molecular weight and is inserted within the polymeric matrix. However, this lignin biomolecule retains its antioxidant behavior as the temperature is increased in the process to a greater degree than the commercial antioxidant.

\section{Conflict of Interests}

The authors declare that there is no conflict of interests regarding the publication of this paper.

\section{Acknowledgments}

The authors would like to acknowledge INDESCA (Ana Maria Campos Petrochemical Complex) for their support in the use of equipment and CONDES-LUZ (CC-025914 Program) and FONACIT (Project G-2005000454) for financial support. The authors' heartfelt thanks go to Dr. Šimon for providing them with support program calculation.

\section{References}

[1] I. Roca, Estudio de las propiedades y aplicaciones industriales del polietileno de alta densidad (HDPE) [Ph.D. thesis], Universidad San Carlos de Guatemala, Guatemala City, Guatemala, 2005.

[2] A. Peacock, Handbook of Polyethylene: Structures, Properties, and Applications, vol. 57th of Eighteenth-Century English Drama, chapter 5, 2000.

[3] I. Piña, F. Ysambertt, M. Arias, J. Chirinos, and M. Castillo, "Capacidad Antioxidante de la lignina extraída del licor negro en polietileno de baja densidad," Revista Iberoamericana de Polímeros, vol. 12, 2011.
[4] P. Šimon, D. Hynek, M. Malíková, and Z. Cibulková, “Extrapolation of accelerated thermooxidative tests to lower temperatures applying non-Arrhenius temperature functions," Journal of Thermal Analysis and Calorimetry, vol. 93, no. 3, pp. 817-821, 2008.

[5] Z. Cibulková, P. Šimon, P. Lehocký, and J. Balko, "Antioxidant activity of $p$-phenylenediamines studied by DSC," Polymer Degradation and Stability, vol. 87, no. 3, pp. 479-486, 2005.

[6] I. Piña, J. Chirinos, F. Ysambertt, and M. Arias, "Estudio termoxidativo no isotérmico por calorimetría diferencial de barrido de polietileno de baja densidad formulado con lignina," Avances en Ciencias e Ingeniería, vol. 3, no. 3, pp. 83-90, 2012.

[7] S. Tiptipakorn, S. Damrongsakkul, S. Ando, K. Hemvichian, and S. Rimdusit, "Thermal degradation behaviors of polybenzoxazine and silicon-containing polyimide blends," Polymer Degradation and Stability, vol. 92, no. 7, pp. 1265-1278, 2007.

[8] E. B. Zeynalov and N. S. Allen, "Modelling light stabilizers as thermal antioxidants," Polymer Degradation and Stability, vol. 91, no. 12, pp. 3390-3396, 2006.

[9] A. Gregorová, B. Košíková, and R. Moravčík, "Stabilization effect of lignin in natural rubber," Polymer Degradation and Stability, vol. 91, no. 2, pp. 229-233, 2006.

[10] R. Yang, L. Lucia, A. Ragauskas, and H. Jameel, "Oxygen degradation and spectroscopic characterization of hardwood kraft lignin," Industrial and Engineering Chemistry Research, vol. 41, no. 24, pp. 5941-5948, 2002.

[11] P. M. Froass, A. J. Ragauskas, and J.-E. Jiang, "Nuclear magnetic resonance studies. 4. Analysis of residual lignin after kraft pulping," Industrial and Engineering Chemistry Research, vol. 37, no. 8, pp. 3388-3394, 1998.

[12] H. L. Hergert, "Infrared spectra of lignin and related compounds. II. Conifer lignin and model compounds," Journal of Organic Chemistry, vol. 25, no. 3, pp. 405-413, 1960.

[13] S.-I. Tohmura and D. S. Argyropoulos, "Determination of arylglycerol- $\beta$-aryl ethers and other linkages in lignins using DFRC/31P NMR," Journal of Agricultural and Food Chemistry, vol. 49, no. 2, pp. 536-542, 2001.

[14] A.-A. M. A. Nada, M. El-Sakhawy, and S. M. Kamel, "Infrared spectroscopic study of lignins," Polymer Degradation and Stability, vol. 60, no. 2-3, pp. 247-251, 1998.

[15] A.-A. M. A. Nada, M. A. Yousef, K. A. Shaffei, and A. M. Salah, "Infrared spectroscopy of some treated lignins," Polymer Degradation and Stability, vol. 62, no. 1, pp. 157-163, 1998.

[16] E. R. E. Van der Hage, W. M. G. M. van Loon, J. J. Boon, H. Lingeman, and U. A. T. Brinkman, "Combined highperformance aqueous size-exclusion chromatographic and pyrolysis-gas chromatographic-mass spectrometric study of lignosulphonates in pulp mill effluents," Journal of Chromatography $A$, vol. 634, no. 2, pp. 263-271, 1993.

[17] A. Majcherczyk and A. Hüttermann, "Size-exclusion chromatography of lignin as ion-pair complex," Journal of Chromatography A, vol. 764, no. 2, pp. 183-191, 1997.

[18] E. Sjöholm, K. Gustafsson, and A. Colmsjö, "Size exclusion chromatography of lignins using lithium chloride/N,Ndimethylacetamide as mobile phase. I. Dissolved and residual birch kraft lignins," Journal of Liquid Chromatography \& Related Technologies, vol. 22, no. 11, pp. 1663-1685, 1999.

[19] F. Ysambertt, R. Bauza, O. Rojas, N. Berrio, N. Márquez, and J.-L. Salager, "Interferencias analíticas asociadas al estudio de la distribución de pesos moleculares en fase orgánica de desechos lígnicos del pulpado de papel," Multiciencias, vol. 4, no. 1, pp. $7-15,2004$. 
[20] C. Pouteaua, P. Dolea, B. Cathalaa, L. Averousa, and N. Boquillonb, "Antioxidant properties of lignin in polypropylene," Polymer Degradation and Stability, vol. 81, no. 1, pp. 9-18, 2003.

[21] A. Gregorová, Z. Cibulková, B. Košíková, and P. Šimon, "Stabilization effect of lignin in polypropylene and recycled polypropylene," Polymer Degradation and Stability, vol. 89, no. 3, pp. 553-558, 2005.

[22] I. Piña, Estudio de la capacidad antioxidante de lignina $y$ derivados lígnicos en polietileno de baja densidad [Ph.D. thesis], Universidad del Zulia, Maracaibo, Venezuela, 2011.

[23] R. Van Grieken, A. Carrero, I. Suarez, and B. Paredes, "Study of the 'in-situ blended' method for polyethylene/clay preparation: effect of clay pretreatment," Journal of Nanostructured Polymers and Nanocomposites, vol. 6, no. 3, pp. 79-86, 2010.

[24] R. A. García, A. Carrero, C. Martín, and C. Domínguez, "Effects of the structural components on slow crack growth process in polyethylene blends. Composition intervals prediction for pipe applications," Journal of Applied Polymer Science, vol. 121, no. 6, pp. 3269-3276, 2011. 

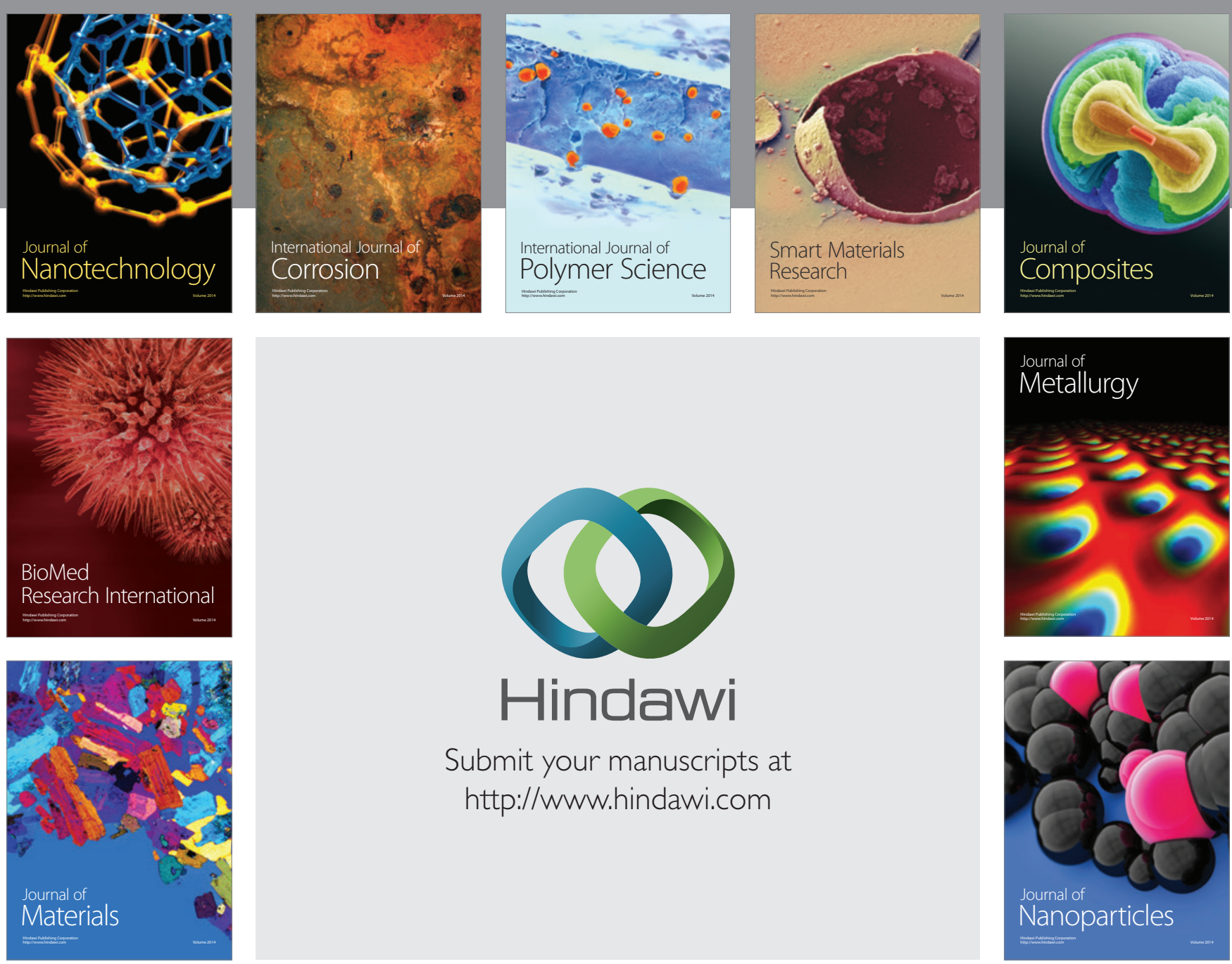

Submit your manuscripts at http://www.hindawi.com
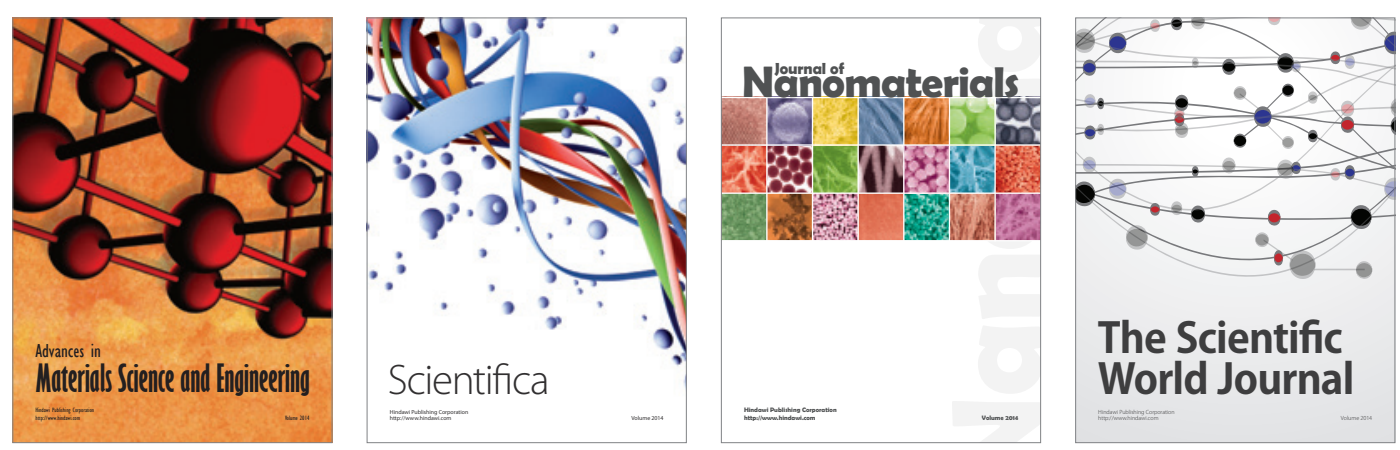

\section{The Scientific World Journal}
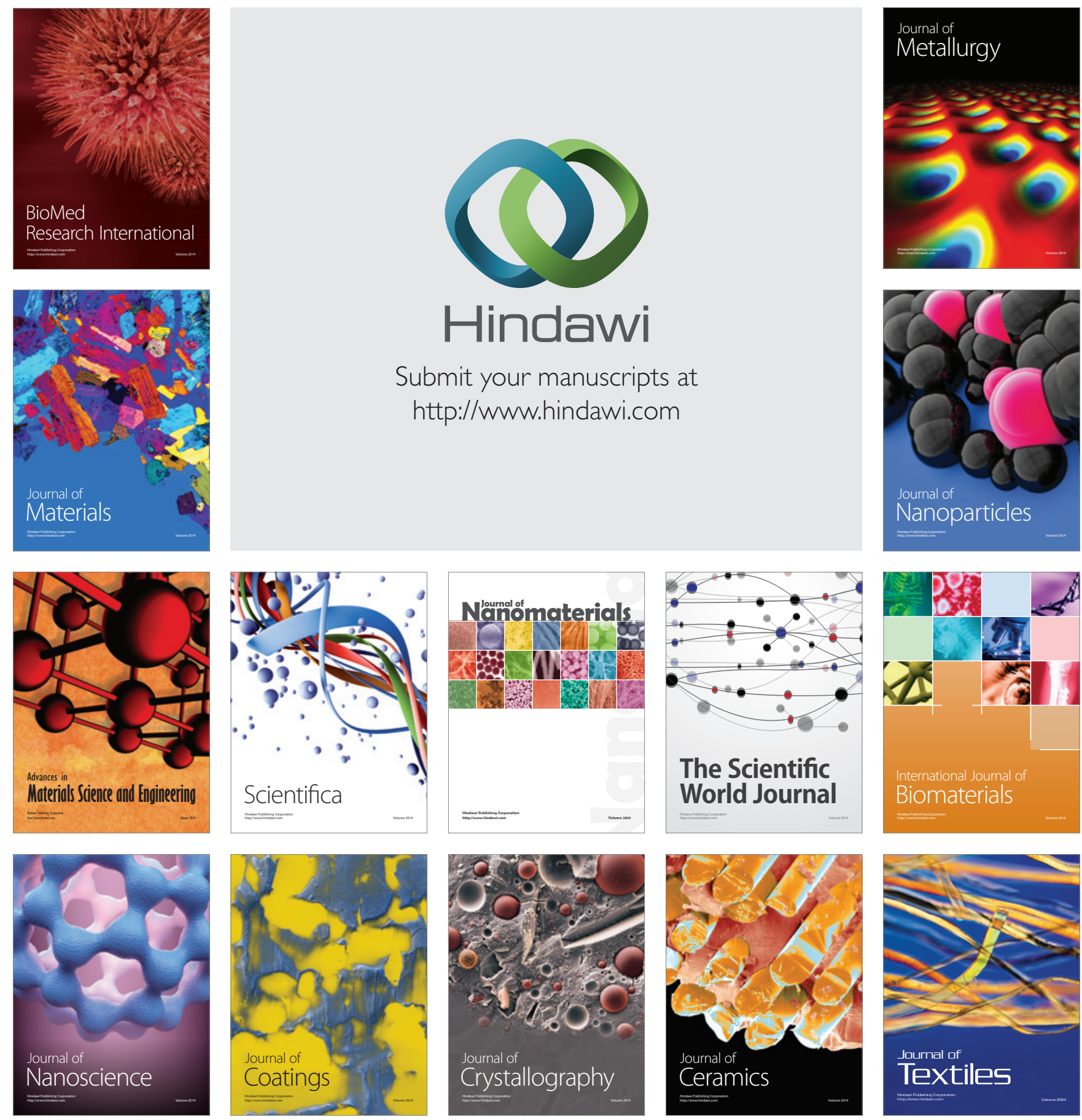